\title{
Notes
}

Nicolas Salamanca* and Jan Feld

\section{A Short Note on Discrimination and Favoritism in the Labor Market}

DOI 10.1515/bejte-2016-0133

Abstract: We extend Becker's model of discrimination by allowing firms to have discriminatory and favoring preferences simultaneously. We draw the twopreference parallel for the marginal firm, illustrate the implications for wage differentials, and consider the implied long-run equilibrium. In the short-run, wage differentials depend on relative preferences. However, in the long-run, market forces drive out discriminatory but not favoring firms.

Keywords: wage gap, nepotism, firm preferences, long-run equilibrium JEL Classification: J70, J31

\section{Introduction}

Becker's (1957) theory is well established as the cornerstone of discrimination in economics, and has spurred the immense literature on this topic for over half a century. He models discrimination as firms' distaste for interacting with certain groups of workers. Firms then act as if workers from that group would carry a wage premium, thus making them less attractive for hiring. The key result from Becker's model is that it is the preference of the marginal discriminator - the firm that is indifferent between hiring from the discriminated group - that determines the wage gap, a powerful insight that helps us understand the interaction between markets and preferences both theoretically and empirically (see Charles and Guryan 2008). One oft cited limitation

\footnotetext{
*Corresponding author: Nicolas Salamanca, Melbourne Institute of Applied Economic and Social Research, University of Melbourne, Carlton, Victoria, Australia; Institute for the Study of Labor (IZA), Bonn, Nordrhein-Westfalen, Germany, E-mail: n.salamanca@unimelb.edu.au Jan Feld, School of Economics and Finance, Victoria University of Wellington, Wellington, New Zealand; Institute for the Study of Labor (IZA), Bonn, Nordrhein-Westfalen, Germany, E-mail: jan.feld@vuw.ac.nz
} 
of this model, however, is that it predicts that market forces will make discriminatory firms disappear in the long run. This prediction is not supported by the data. Building on Becker's model, Goldberg (1982) has shown that the long-run wage differential can persist if firms have favoring instead of discriminatory preferences. The key difference is that favoring firms get nonpecuniary benefits from hiring their preferred workers and thus remain in the market even though they make lower profits.

Both Becker and Goldberg assume that firms only have preferences towards one group. Conceptually, however, there is no reason to believe that discriminatory and favoring preferences are mutually exclusive (see e. g., Allport 1954). And empirically, data from the US General Social Survey (GSS), for example, suggests that these two preferences are not simply flipsides of one another; in the GSS, the correlation between the respondent's expressed "closeness to Whites" and their "closeness to Blacks" is around 0.24, far from the -1 correlation that indistinguishable preferences would imply (Feld, Salamanca, and Hamermesh 2016, 1505). Finally, for the formulation and evaluation of policies the difference between discrimination and favoritism can be essential. Hotly debated outcome gaps, such as the gender wage gap or racial gaps in criminal prosecution, are only differences in outcomes between groups that can be attributed to discrimination, favoritism, or both. Social suasion campaigns against favoritism or discrimination can therefore have varying degrees of effectiveness depending on the preference or combination of preferences that drive those gaps.

A number of recent experimental studies have made remarkable progress in separately identifying discriminatory and favoring preferences. This is typically done by benchmarking outcomes using a comparison group towards which people feel arguably neutral, either because this group has no identifying characteristics (Fershtman, Gneezy, and Verboven 2005; Feld, Salamanca, and Hamermesh 2016) or because the group's characteristics are not recognizable (Jacquemet and Yannelis 2012; Edo, Jacquemet, and Yannelis 2015). Using this approach, favoritism is identified as a positive treatment relative the neutral group, and discrimination is identified as a negative treatment relative to the neutral group. Importantly, the findings of this literature confirm that both favoring and discriminatory preferences co-exist, which raises the question: How do discrimination and favoritism jointly affect outcomes in the short- and the long-run? In this short note, we answer this question by extending Becker's model of discrimination, allowing firms to have discriminatory and favoring preferences simultaneously. We draw the two-preference parallel for the marginal firm, illustrate the implications for wage differentials, and consider the implied long-run equilibrium. 


\section{A Theory of Discrimination and Favoritism}

To model firms with both discriminatory and favoring preferences we keep to Goldberg's (1982) notation and structure. Consider a firm that faces market wages $W_{b}$ for Blacks and $W_{w}$ for Whites, but acts as if the unit cost of labor were $W_{b}\left(1+d_{b}\right)$ and $W_{w}\left(1-d_{w}\right)$, where $d_{b}$ and $d_{w}$ are the "discrimination" and "favoritism" coefficients, respectively. The firm's profit function is

$$
\pi=Q\left(L_{b}+L_{w}\right)-W_{b} L_{b}-W_{w} L_{w}
$$

and its utility function

$$
U=\pi-d_{b} W_{b} L_{b}+d_{w} W_{w} L_{w}=Q\left(L_{b}+L_{w}\right)-W_{b}\left(1+d_{b}\right) L_{b}-W_{w}\left(1-d_{w}\right) L_{w}
$$

where $L$ represents employment, and $Q$ is a well-behaved production function where the labor of Blacks and Whites are perfect substitutes. Following Becker, we assume that the discrimination coefficient is non-negative, and following Goldberg, we assume that the favoritism coefficient is non-negative and strictly smaller than one to ensure a finite demand for White workers.

Because of the perfect substitution in production, the firm hires only Black or only White workers depending on which effective wage (i. e., the wage after considering both discriminatory and favoritism preferences) is lower. In particular, firms will hire only Blacks if

$$
W_{b}\left(1+d_{b}\right)<W_{w}\left(1-d_{w}\right)
$$

and only Whites if

$$
W_{b}\left(1+d_{b}\right)>W_{w}\left(1-d_{w}\right)
$$

We can thus express the condition for a firm to hire only Black workers as

$$
\frac{W_{b}}{W_{w}}=w<\frac{\left(1-d_{w}\right)}{\left(1+d_{b}\right)}
$$

where $w$ represents the ratio between Black and White wages. We assume that Black wages are less than White wages, so that $w<1$, a condition that holds in equilibrium.

For a set level of relative wages which the firms take as given, the combination of preferences that would result in firms hiring Black or White workers in the short-run is depicted in Figure 1. Notice that in the figure Becker's and Goldberg's models are subsumed by movements on the $y$-axis and $x$-axis, respectively. Displacing the firm's preference against Blacks on the $y$-axis (and thus taking $d_{w}=0$ ) shows that the firm starts hiring Whites when $d_{b}>1 / w-1$, or 


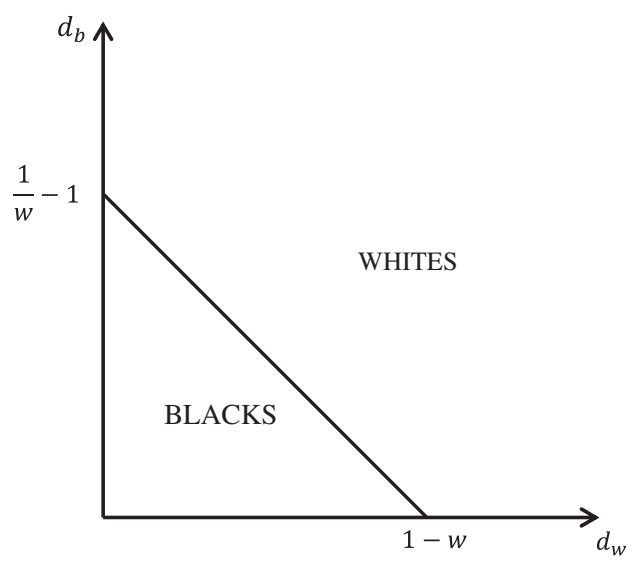

Figure 1: Preferences for whites and against blacks and the demand for white or black labor.

equivalently when $W_{b}\left(1+d_{b}\right)>W_{w}$, the condition in Becker's scenario. Displacing the firm's preferences for Whites on the $x$-axis (and thus taking $d_{b}=0$ ) shows that the firm starts hiring Whites when $d_{w}>1-w$, or equivalently when $W_{w}\left(1-d_{w}\right)<W_{b}$, the condition in Goldberg's scenario.

More generally, Figure 1 shows all combinations of discriminatory and favoring preferences of the firms that hire Blacks or Whites given an observed set of market wages. The diagonal line in the figure shows which firms are indifferent between hiring Whites or Blacks - the marginal firms. The figure also unpacks a surprisingly powerful insight: through it we can make sense of most apparent mismatches between firms' preferences and their hiring decisions. In Becker's scenario, where only discrimination matters, every firm that hires Blacks will have less discriminatory preferences than any firm that hires Whites. Goldberg's scenario parallels this idea with favoritism. In our model firms will hire Blacks or Whites according to their relative preferences $\left(1-d_{w}\right) /\left(1+d_{b}\right)$ but, when focusing on a single preference, it is perfectly possible that a highly discriminating (favoring) firm hires Blacks while a less discriminating (favoring) one hires Whites.

Labor demand, represented by the function $R$, the inverse function of $Q^{\prime}$, will also depend on both preferences. The simplest way to understand how labor demand evolves with both preferences is to first see how it evolves with each preference while holding the other preference constant. Figures 2 and 3 illustrate these conditional labor demand functions.

Reflecting the fact that $d_{b}$ acts as a wage premium, Figure 2 shows that labor demand decreases with discriminatory preferences among firms who hire Blacks. Analogously, Figure 3 shows that labor demand increases with 

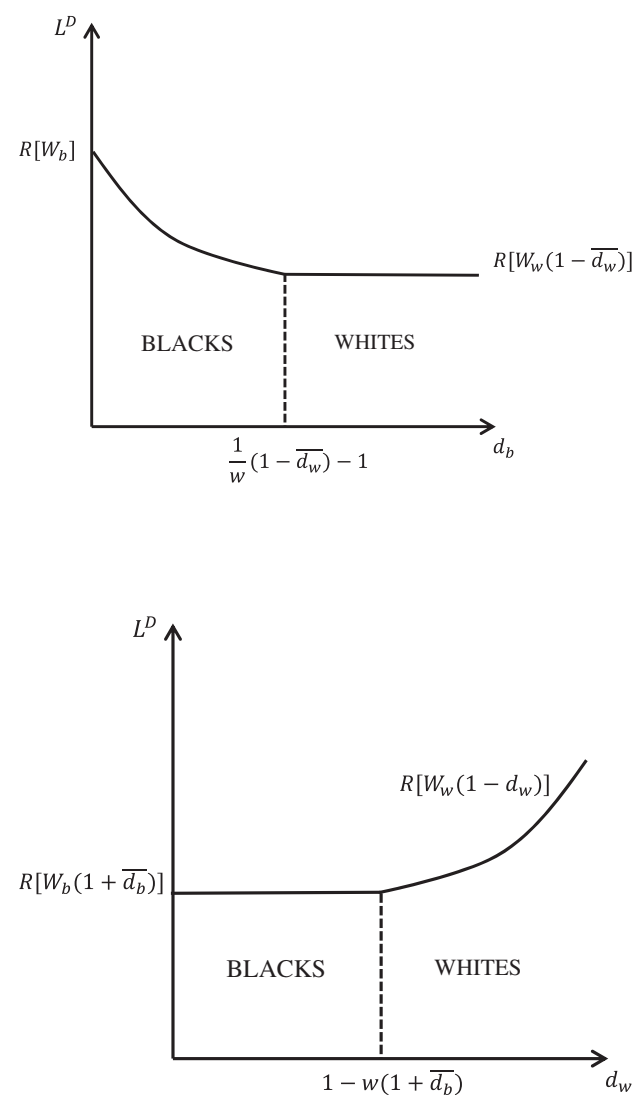

Figure 2: Labor demand as a function of preferences against blacks for a given level $\overline{d_{w}}$ of preferences for whites.

Figure 3: Labor demand as a function of preferences for whites for a given level $\overline{d_{b}}$ of preferences against blacks.

favoritism preferences among firms who hire Whites. The flat part of the curves reflects the fact that, at a certain level of each preference, the hiring decision changes from Blacks to Whites. At that point the preference for the obverse group ceases to matter for the hiring intensity.

It is also worth noting that both these conditional labor demands are continuous at every point, ensuring that the overall labor demand will also be continuous. This in turn results in a smooth production process without any discrete jumps in the entire domain of $\left(d_{w}, d_{b}\right)$. Importantly, this labor demand is continuous at the critical values where $w=\left(1-d_{w}\right) /\left(1+d_{b}\right) .{ }^{1}$

1 Continuity at these critical points, and the continuity of the utility functions that ensues, can be shown just as in Goldberg (1982, 310, footnote 3). 
Stemming from these preferences, the aggregate labor demands can be expressed as

$$
\int_{0}^{1} \int_{0}^{\frac{1}{w}\left(1-d_{w}\right)-1} R\left[w_{b}\left(1+d_{b}\right)\right] f\left(d_{b}, d_{w}\right) d_{b} d_{w}
$$

for Blacks, and

$$
\int_{0}^{1} \int_{\frac{1}{w}\left(1-d_{w}\right)-1}^{\infty} R\left[w_{w}\left(1-d_{w}\right)\right] f\left(d_{b}, d_{w}\right) d_{b} d_{w}
$$

for Whites, where $f\left(d_{b}, d_{w}\right)$ represents the joint distribution of favoritism and discrimination in the population of firms. ${ }^{2}$

The equilibrium wages are a result of equating each of these demands with the respective labor supplies of Blacks and Whites, $S_{w}\left(w_{w}\right)$ and $S_{b}\left(w_{b}\right)$. As in Becker and in Goldberg, wages for Blacks and Whites are thus determined by the supply of Black and White workers and the firm's preferences by solving the resulting 2-equation 2-unknown system. In contrast with Becker's and Goldberg's scenarios, though, the marginal discriminator will be defined by the relative preferences $\left(1-d_{w}\right) /\left(1+d_{b}\right)$ and not by either $d_{b}$ or $d_{w}$ individually. The increases or decreases in the preferences of the marginal discriminator will be governed by the joint distribution $f\left(d_{b}, d_{w}\right)$ and unless this distribution is known we will not be able to map these changes to the separate changes in $d_{b}$ and $d_{w}{ }^{3}$

To understand how the profits and the utility of the firm behave as discrimination and favoritism change, Figures 4 and 5 plot them both against each preference while holding the other one constant.

A few important features of the graphs are worth highlighting. First, profits are always decreasing in favoritism and discrimination, reflecting the fact that both preferences distort the profit-maximizing level of employment chosen by the firm. Second, the discontinuous drop in profits when the firm switches from hiring Blacks to hiring Whites further shows that discriminatory and favoring preferences damage profits by distorting the type of labor chosen too. Third, the

2 Note that with this parameterization of preferences the preference support that ensures strictly positive wages is $[0,1)$ for $d_{w}$ and f. This support bounds the limits on the integrals in (4) and (5).

3 Note also that a wage gap cannot exist in equilibrium if there is neither favoritism nor discrimination. To see this, set $d_{b}$ and $d_{w}$ to zero in Figures 2 and 3 and notice that, given a well-defined supply of Blacks and Whites, firms will want to hire either for a set - and equal wage. 

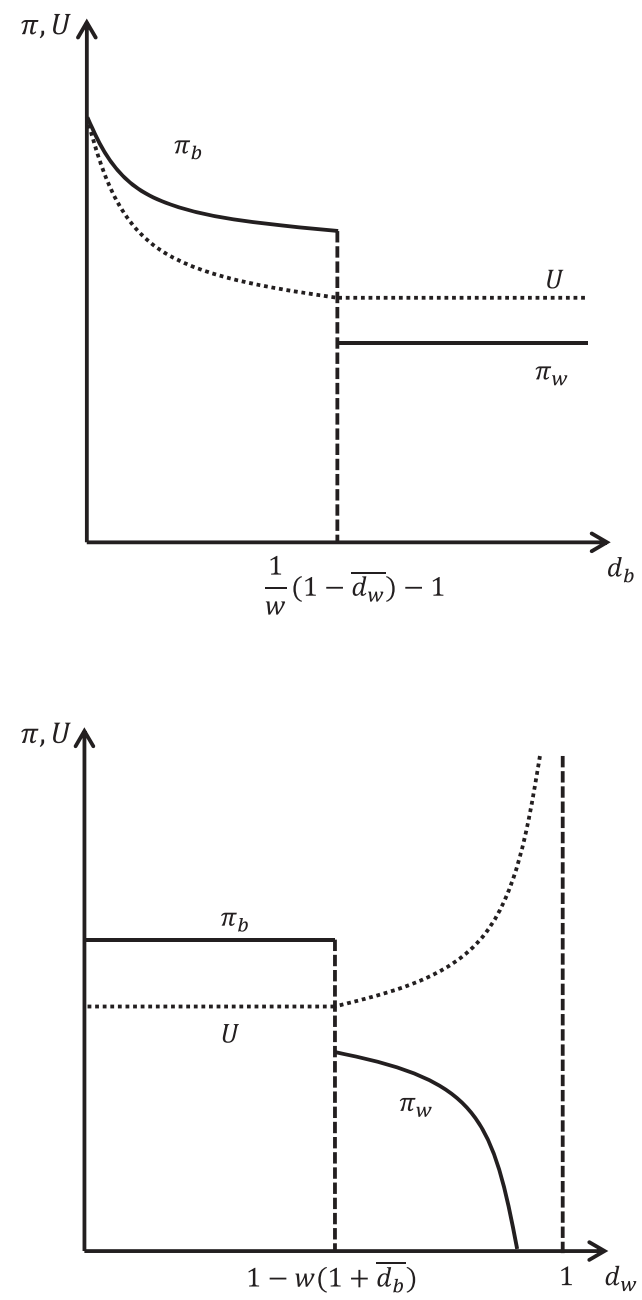

Figure 4: Profits and utility as a function of preferences against blacks for a given level $\overline{d_{w}}$ of preferences for whites.

Figure 5: Profits and utility as a function of preferences for whites for a given level $\overline{d_{b}}$ of preferences against blacks.

firm's utility is less than the profits when the firm hires Blacks, and exceeds profits when the firms hire Whites. This utility is continuous throughout the range of preferences and will play a key role in determining which firms are expected to survive in the long-run. Fourth, there is a level of favoritism above which the firm will have negative profits, and this level depends exclusively on the equilibrium wage for Whites. A firm with this preference will not survive, even in the short-run.

Which firms will survive in the long-run? Following the argument in Becker (1957), laid out in standard labor economics textbooks (e. g., Ehrenberg and 
Smith 2009, Ch. 12; Cahuc, Carcillo, and Zylberberg 2014, Ch. 8) and developed in detail by Goldberg $(1982,313)$, a firm survives in the long-run if it cannot be bought out and operated by another firm. For such a transaction to take place, the profits of the buyer firm have to be larger than the utility of the seller firm (assuming that there are borrowing constraints for firms). The intuition behind this is that the buyer needs to compensate the seller for its utility, which is determined not only by profits but also by non-pecuniary benefits or losses.

With this framework in mind, let us categorize the transactions that would take place in the long-run based on Figures 4 and 5. Upon inspection of Figure 4 we can see that all firms with positive discriminatory preferences can be bought by a firm that does not discriminate. This happens because discriminatory firms will always suffer a disutility as long as they hire Blacks. When that disutility is large enough that they would rather hire Whites, their profits suffer from having to pay the higher equilibrium wages, which will hurt their profits. And, at that level of profits, they cannot acquire any other discriminatory firm. Therefore, in the long-run firms with discriminatory preferences should disappear.

What about transactions amongst favoring firms? As shown in Figure 4, when discriminatory firms disappear the gap between the profits of favoring firms when they hire Blacks, $\pi_{b}$, and their utility, $U$, disappears with them. Figure 5 then shows that once that happens there will be no firm with profits that strictly exceed any other firm's utility. Therefore, no transactions will take place amongst firms with any level of favoritism, ensuring that in the long-run firms of all levels of favoritism that make positive profits in the short-run can survive.

The long-run results show that even though in the short-run a variety of preferences consistent with Becker's discrimination and Goldberg's favoritism can co-exist, in the long-run market forces will drive out discriminatory but not favoring firms, just as Goldberg shows.

\section{Conclusions}

In this paper we extend Becker's model of discrimination and Goldberg's model of favoritism to include both discriminatory and favoring preferences simultaneously. The model draws parallel definitions for the firm's utility, profit, and labor demand functions, extends the conditions for market equilibrium, and redefines the marginal discriminator in terms of relative discriminatory and 
favoring preferences. It also shows that in the long-run only favoring but not discriminatory firms can exist.

The short-run dynamics of this model and the redefinition of the marginal discriminator in terms of relative preferences can yield useful insights for analyzing markets where market forces that drive out discrimination are not (yet) at play. Future empirical research can show whether discriminatory preferences, favoring preferences, or both, can best explain market wage gaps and outcome gaps that can be attributed to systematic differential treatment of groups. In particular, one could use measures of discriminatory and favoring attitudes, analogously to Charles and Guryan (2008), to see which model best explains wage gaps and how they have evolved over time. Together with our framework, this exercise can provide powerful insights into the role of employer preferences in determining wage gaps.

Acknowledgments: We thank Melisa Bubonya, Matthew Goldberg, Jongsay Yong, and especially Dan Hamermesh for their comments on earlier drafts. This research was partly supported by the Australian Research Council Centre of Excellence for Children and Families over the Life Course (project number CE140100027). The Centre is administered by the Institute for Social Science Research at The University of Queensland, with nodes at The University of Western Australia, The University of Melbourne and The University of Sydney.

Funding: Australian Research Council Centre of Excellence for Children and Families over the Life Course (Grant/Award Number: CE140100027).

\section{References}

Allport, G. W. 1954. The Nature of Prejudice. Cambridge, MA: Addison-Wesley.

Becker, G. S. 1957. The Economics of Discrimination. Chicago, IL: University of Chicago Press. Cahuc, P., S. Carcillo, and A. Zylberberg. 2014. Labor Economics. Cambridge, MA: MIT Press.

Charles, K. K., and J. Guryan. 2008. "Prejudice and Wages: An Empirical Assessment of Becker's the Economics of Discrimination." Journal of Political Economy 116 (5):773-809.

Edo, A., N. Jacquemet, and C. Yannelis. 2015. "Language Skills and Homophilous Hiring Discrimination: Evidence from Gender-and Racially-Differentiated Applications.” Unpublished manuscript.

Ehrenberg, R. G., and R. S. Smith. 2009. Modern Labor Economics: Theory and Public Policy. Boston, MA: Pearson/Addison-Wesley.

Feld, J., N. Salamanca, and D. S. Hamermesh. 2016. "Endophilia or Exophobia: Beyond Discrimination“. The Economic Journal 126:1503-27. 
Fershtman, C., U. Gneezy, and F. Verboven. 2005. "Discrimination and Nepotism: The Efficiency of the Anonymity Rule." The Journal of Legal Studies 34 (2):371-96.

Goldberg, M. S.. 1982. "Discrimination, Nepotism, and Long-Run Wage Differentials." The Quarterly Journal of Economics 97 (2):307-19.

Jacquemet, N., and C. Yannelis. 2012. "Indiscriminate Discrimination: A Correspondence Test for Ethnic Homophily in the Chicago Labor Market.” Labour Economics 19 (6):824-32. 